\title{
Impact of Body Composition in Overweight and Obese Patients With Localised Renal Cell Carcinoma
}

\author{
TIFFANY DARBAS ${ }^{1}$, GERAUD FORESTIER ${ }^{2}$, SOPHIE LEOBON ${ }^{1}$, JULIA PESTRE ${ }^{1}$, PIERRE JESUS ${ }^{3}$, \\ DENIS LACHATRE $^{2}$, NICOLE TUBIANA-MATHIEU ${ }^{1}$, AURELIEN DESCAZEAUD ${ }^{4}$ and ELISE DELUCHE ${ }^{1}$ \\ ${ }^{1}$ Department of Medical Oncology, Limoges University Hospital, Limoges, France; \\ ${ }^{2}$ Department of Radiology, Limoges University Hospital, Limoges, France; \\ ${ }^{3}$ Nutrition Unit, Limoges University Hospital, Limoges, France; \\ ${ }^{4}$ Department of Urology, Limoges University Hospital, Limoges, France
}

\begin{abstract}
Background/Aim: To investigate the impact of body composition on morbidity and mortality at the initial diagnosis of localised renal cell carcinoma (RCC) in patients with overweight or obesity. Patients and Methods: Sarcopenia was defined using sex-specific cut-off points and other body composition parameters by median values with computed tomography imaging. Results: Among the 96 patients, 40 had sarcopenia (43.0\%) at diagnosis. Body composition had no effect on morbidity and 5-year diseasefree survival contrary to the classic factors $(p<0.05)$. In the subgroup of obese patients, those with sarcopenia had a poor prognosis $(p=0.04)$ but not in the population with overweight $(p=0.9)$. Conclusion: Sarcopenia was frequently associated with localised RCC at the initial diagnosis. Body composition did not affect morbidity or outcomes. BMI was involved in morbidity and there was paradoxically longer survival in the obesity group.
\end{abstract}

Most diagnoses of renal cell cancer (RCC) are performed when the disease is at a localised stage with a potentially curative treatment (1). Malnutrition is a poor prognostic factor for RCC regardless of the stage (2). While body mass index (BMI) distinguishes the nutritional status of patients, it does not differentiate between lean mass and fat mass. Thus, some studies have demonstrated that body composition parameters could produce interesting results (3). Among

This article is freely accessible online.

Correspondence to: Elise Deluche, Medical Oncology, Limoges University Hospital, 2 avenue Martin Luther King, 87042 Limoges Cedex, France. Tel: +33 555056100, Fax: +33 555056319, e-mail: elise.deluche@chu-limoges.fr

Key Words: Renal cell carcinoma, skeletal muscle mass, sarcopenia, overweight, obesity. body composition factors, decreased skeletal muscle mass, commonly known as sarcopenia, is associated with decreased efficacy of treatment, increased toxicity of cancer therapy (4), increased frequency of postoperative complications (5), and poor patient outcomes (6) in different cancers.

Most kidney cancer studies have been performed in a metastatic setting and have demonstrated that sarcopenia has a negative impact on treatment tolerance $(7,8)$ as well as overall survival (OS) (9-12). By contrast, there is discordance regarding the impact of sarcopenia on localised RCC, length of hospital stay and survival after curative treatment $(13,14)$.

In parallel, obesity is significantly associated with RCC [body mass index $35 \mathrm{vs} .<25 \mathrm{~kg} / \mathrm{m}^{2}$ : hazard ratio $(\mathrm{HR})=1.71$, 95\% CI $=1.06-2.79]$ in Europe (15). Despite a high frequency of overweight/obese patients with localised RCC, the impact of sarcopenia has not been studied in this specific overweight or obese population, even if sarcopenic obesity has a negative impact on the management of other cancers (16-18). Less is known about myosteatosis, which is a pathological infiltrate by muscle fat that can be assessed by computed tomography (CT) imaging using muscle radiodensity or skeletal muscular density (SMD) (14). One study showed that low muscle density, which reflects low muscle quality, seems to have higher impact on survival of patients with metastatic RCC than with sarcopenia (19). Furthermore, it is related to the prognosis in other cancers $(20,21)$.

In this study, we assessed the impact of body composition (studied by CT scans) on morbidity and outcomes in an overweight or obese population with localised RCC.

\section{Patients and Methods}

Study design and patients. We performed a retrospective study that included patients with localised RCC who were treated at Limoges University Hospital from January 2006 to December 2017. The patients were selected according to the following criteria: adults aged $>18$ years who were overweight or obese, as assessed via BMI $\left(\mathrm{kg} / \mathrm{m}^{2}\right)$ at diagnosis; a CT scan performed before surgery in our 
institution to assess body composition; patients who received a nephrectomy (partial or radical) without adjuvant treatment.

Patients with metastatic disease, lymph node involvement at diagnosis, or with other neoplasia (being treated or treated $<5$ years ago) were excluded.

Clinical data were collected in accordance with French bioethics laws regarding patient information and consent. Data collection and use were approved by Limoges Hospital Ethics Committee (approval number: $2165046 \mathrm{v}$ 0).

Assessments and procedures. Clinical and biological characteristics. The following data were collected at the initial diagnosis: comorbidities (the presence of smoking, high blood pressure and diabetes), age and performance status (PS); pathological characteristics, such as TNM staging, histology, number of metastatic sites; stage, size, grade and necrosis (SSIGN) (22) and USLA integrated staging system (UISS) scores (23); and surgical characteristics, including partial or radical nephrectomy, adrenalectomy, and thrombectomy.

Selected data were collected using CROSSWAY software (patient data management software, licensed to the hospital) and from handwritten patient records

Anthropometric measures. Weight and height were documented from the patient's anaesthesia records or the surgeon's consultation report at the diagnosis. BMI was calculated, and categories were defined according to the World Health Organization as follows: overweight, $25-29.9 \mathrm{~kg} / \mathrm{m}^{2}$ and obese, $\geq 30 \mathrm{~kg} / \mathrm{m}^{2}$.

CT scan imaging. CT scans with intravenous contrast agent were performed at Limoges University Hospital. Images were retrieved from digital storage in the Picture Archiving and Communication System (TELEMIS society). The image analyses were performed by a radiologist blinded to the patients' survival status, using AW software (GE Healthcare, 2018 General Electric Co, Buc, Yvelines, France) and performed as described previously (24).

Skeletal muscle mass (SMM), visceral adipose tissue (VAT), subcutaneous adipose tissue (SAT), and infiltration inter-muscular adipose tissue (IMAT) $\left(\mathrm{cm}^{2}\right)$ were evaluated on a single image at the third lumbar vertebrae (L3) using Hounsfield unit thresholds (HU): muscle ( -29 to 150$)$, visceral adipose tissue $(-150$ to -50$)$, subcutaneous adipose tissue, and inter-muscular adipose tissue (190 to -30$)$.

The skeletal muscle index (SMI), VAT index, SAT index, and IMAT index in $\mathrm{cm}^{2} / \mathrm{m}^{2}$ were defined by tissue cross-sectional area $\left(\mathrm{cm}^{2}\right)$ normalised to square meters $\left(\mathrm{m}^{2}\right)$. To evaluate myosteatosis or SMD, mean attenuation in HU was used as described previously (16). SMD was quantified as the muscle cross-sectional area across the L3 vertebral body level and was assessed between -29 and +150 HU. Muscle density assessed by this method reflects fatty muscle infiltration.

Study end-points. The primary objective was to assess the impact of BMI and body composition on morbidity and outcomes among a population of overweight or obese individuals with localised RCC. We also evaluated the correlation between body composition and BMI.

Sarcopenia was defined using sex-specific SMI cut-off points: $<41 \mathrm{~cm}^{2} / \mathrm{m}^{2}$ (females) and $<53 \mathrm{~cm}^{2} / \mathrm{m}^{2}$ (males) (9). Similar to previous studies, a threshold of median was the choice for SMD to define myosteatosis $(9,16)$. Cut-off points for VAT, SAT, and the IMAT indices were based on median values (25).
Morbidity was defined by infections requiring post-surgical treatment or increased length of hospital stay.

Infection was diagnosed if a patient had fever or needed antibiotics for up to 1 month after the surgical treatment. Length of hospital stay was calculated from the day of treatment to the day of discharge from the urology ward (to home or to a convalescent ward). An extended length of stay was considered $>7$ days after a partial nephrectomy and 10 days after a radical nephrectomy (26).

Disease-free survival (DFS) and OS. DFS was measured as the interval between surgery and the date of first recurrence. OS was calculated from the date of diagnosis to death or the last follow-up. Patients were followed until death or April 31, 2019, at which time they were censored on the last date they were documented to be alive.

Statistical analyses. All data were collected and analysed using STATVIEW software (SAS Institute, Cary, NC, USA) and R software (V.3.5.1; R Foundation for Statistical Computing, Vienna, Austria). Quantitative results are expressed as mean \pm standard deviation or median (range), and qualitative results are expressed as numbers and percentages. Nominal variables were compared between the groups using the chi-square or Fisher's exact tests, as appropriate. Means were compared using the non-parametric MannWhitney $U$-test for continuous variables and the Wilcoxon signedrank test for paired tests. The correlation between BMI and body composition was assessed using Pearson's correlation coefficient analyses.

Survival curves were obtained using the Kaplan-Meier technique. Median survival was compared using the parametric log-rank test. The Cox proportional hazards model was used to evaluate the relationships between variables and survival. Variables with $p<0.10$ in univariate analyses were included in multivariate analyses. $p$ values $<0.05$ were considered significant.

\section{Results}

Characteristics of the patients. Among the 620 patients screened, 96 were included in the final analyses (Figure 1). Most patients were excluded because of an unavailable preoperative CT scan or tomographic artefact. The baseline CT scan used to assess the radiological features with a median delay of 1.7 months (range $=-0.2-10.3$ months) before treatment. The initial characteristics of the patients according to BMI are presented in Table I.

The median BMI of the 96 patients was $29.8 \mathrm{~kg} / \mathrm{m}^{2}$ (range $\left.=25.1-44.1 \mathrm{~kg} / \mathrm{m}^{2}\right)$. Fifty-one patients (53\%) were overweight, and 45 (47\%) obese. Mainly adult men ( $p=0.02)$ were included in the overweight group. No significant differences in PS, RCC risk factors (such as smoking and high blood pressure), TNM classification, histology, type of surgery (partial or radical nephrectomy), or associated procedures (e.g., thrombectomy) were observed between the two groups.

Correlation between body composition and BMI status. Among the patients in the population, $43 \%$ patients $(n=40)$ were sarcopenic (Table II). Some patients with sarcopenia had a 


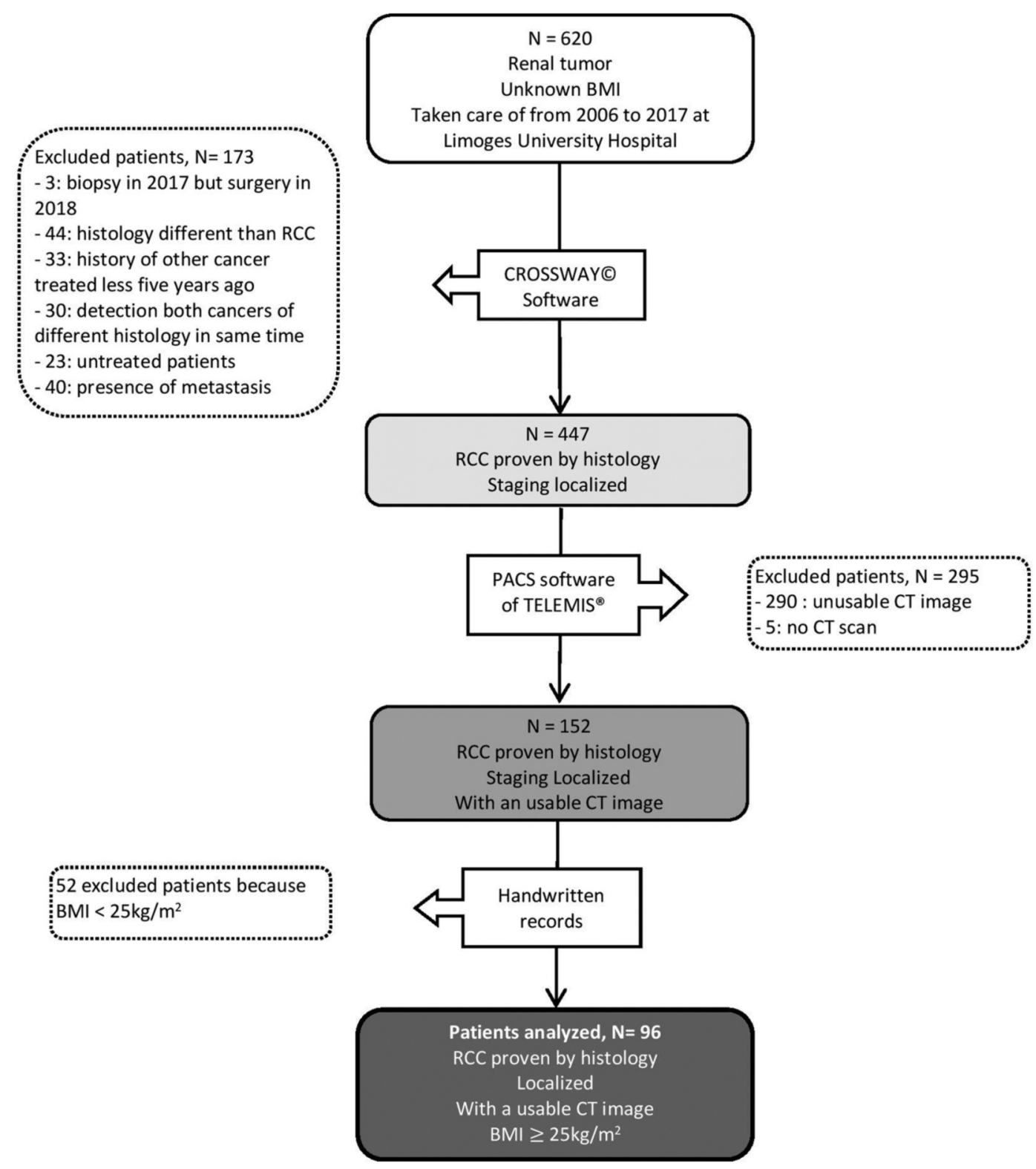

Figure 1. Flow diagram showing patient selection. BMI: Body mass index; CT: computed tomography; N: number of patients; RCC: renal cell carcinoma.

lower BMI than those without sarcopenia (29 vs. 11 patients, $p=0.0009$ ) independently of gender (Table II).

A total of $50.5 \%$ patients had a low $\operatorname{SMD}(n=47)$, and there were no differences according to weight. As expected, patients with obesity had a higher VAT and SAT ( $p=0.0006$ and $p<0.0001$ ) (Table II).

The SMI was related to BMI ( $\mathrm{r}=0.58, p=0.019)$ (Figure 2). $\mathrm{SMI}$ was also more related to BMI in women $(\mathrm{r}=0.55)$ than in men $(r=0.51)$ as shown by the SAT index $(r=0.74$ and $\mathrm{r}=0.53$, respectively).
A moderate correlation was detected between BMI and the VAT and SAT indices $(\mathrm{r}=0.578, p<0.0001$ and $\mathrm{r}=0.506$, $p<0.0001$ ) (Figure 2). No differences in IMAT or SMD were observed between the overweight and obese groups $(\mathrm{r}=-0.116$, $p=0.352$ and $\mathrm{r}=-0.014, p=0.91$ ).

Moreover, only VAT and SAT were slightly related $(\mathrm{r}=0.38, p=0.018)$. The other parameters were not associated.

Impact of body composition on postoperative morbidity. Data on infections were available for 92 patients. Infections 
Table I. Characteristics of the patients.

\begin{tabular}{|c|c|c|c|c|}
\hline & Total & Overweight & Obese & $p$-Value \\
\hline Number of patients & 96 & $51(43)$ & $45(47)$ & \\
\hline Gender & & & & 0.02 \\
\hline Men & $68(70)$ & $41(80)$ & $27(60)$ & \\
\hline Women & $28(30)$ & $10(20)$ & $18(40)$ & \\
\hline PS & & & & 0.4 \\
\hline 0 & $63(66)$ & $35(69)$ & $28(62)$ & \\
\hline 1 & $29(30)$ & $15(29)$ & $14(31)$ & \\
\hline 2 & $4(4)$ & $1(2)$ & $3(7)$ & \\
\hline Age Median (Range) & $66(43-89)$ & $67(43-84)$ & $65(43-89)$ & 0.6 \\
\hline BMI, median $\left(\mathrm{kg} / \mathrm{m}^{2}\right)$ & $29.8(25.1-44.1)$ & $28.3(25.1-29.9)$ & $33.9(30.0-44.1)$ & \\
\hline pTNM & & & & 0.3 \\
\hline pT1a & $29(30)$ & $13(25)$ & $16(36)$ & \\
\hline pT1b & $28(29)$ & $17(33)$ & $11(24)$ & \\
\hline $\mathrm{pT} 2 \mathrm{a} / \mathrm{b}$ & $18(19)$ & $9(18)$ & $9(20)$ & \\
\hline pT3 a/b & $19(20)$ & $10(20)$ & $9(20)$ & \\
\hline pT4 & $2(2)$ & $2(4)$ & $0(0)$ & \\
\hline Histology & & & & 0.2 \\
\hline Clear cell RCC & $81(85)$ & $42(82)$ & $39(87)$ & \\
\hline Papillary RCC & $9(9)$ & $4(8)$ & $5(11)$ & \\
\hline Chromo phobe RCC & $6(6)$ & $5(10)$ & $1(2)$ & \\
\hline Type of surgery & & & & 0.6 \\
\hline Partial nephrectomy & $30(31)$ & $15(30)$ & $15(33)$ & \\
\hline Radical nephrectomy & $66(69)$ & $36(70)$ & $30(67)$ & \\
\hline $\begin{array}{l}\text { Associated procedure: surrenalectomy, } \\
\text { thrombectomy }\end{array}$ & $22(23)$ & $15(29)$ & $7(15)$ & 0.1 \\
\hline \multicolumn{5}{|l|}{ Complications* } \\
\hline Length of stay, days (min-max) & $8.0(3-30)$ & $3.5(3-22)$ & $8.0(3-30)$ & 0.2 \\
\hline >cut-off & $28(30)$ & $11(22)$ & $17(40)$ & 0.06 \\
\hline Infections & $17(18)$ & $4(8)$ & $13(29)$ & 0.007 \\
\hline$>$ cut-off & $2(12)$ & $1(8)$ & $1(25)$ & 0.3 \\
\hline SSGIN score & $\mathrm{N}=90$ & & & 0.2 \\
\hline Low risk & $38(42)$ & $18(37.5)$ & $20(48)$ & \\
\hline Intermediate risk & $17(19)$ & $12(25)$ & $5(12)$ & \\
\hline High risk & $35(39)$ & $18(37.5)$ & $17(40)$ & \\
\hline UISS score & $\mathrm{N}=92$ & & & 0.5 \\
\hline Low risk & $22(24)$ & $10(21)$ & $12(28)$ & \\
\hline Intermediate risk & $14(15)$ & $9(18)$ & $5(12)$ & \\
\hline High risk & $56(61)$ & $30(61)$ & $26(60)$ & \\
\hline
\end{tabular}

*Missing data; BMI: body mass index; PS: performance status.

Table II. Characteristics of body composition according to the body mass index

\begin{tabular}{|c|c|c|c|c|}
\hline & Total & Overweight & Obese & $p$-Value \\
\hline Number & 93 & 44 & 49 & \\
\hline SMI $\left(\mathrm{cm}^{2} / \mathrm{m}^{2}\right):$ median (range) & $50.8(12.6-96.0)$ & $54.4(38.5-96.0)$ & 49.7(13.6-67.4) & 0.02 \\
\hline Sarcopenia: yes $v s$. no & $40(43) / 53(57)$ & $29(60) / 20(40)$ & $11(25) / 33(75)$ & 0.0009 \\
\hline Men: yes vs. no & $33(36) / 32(34)$ & $25(64) / 14(36)$ & $8(30) / 18(70)$ & 0.008 \\
\hline Women: yes vs. no & $7(8) / 21(22)$ & $4(40) / 6(60)$ & $3(17) / 15(83)$ & 0.1 \\
\hline VAT Index $\left(\mathrm{cm}^{2} / \mathrm{m}^{2}\right)$, median (range) & $87.7(16.5-175.0)$ & $78.4(16.5-134.7)$ & $107.4(34.1-175.0)$ & 0.0006 \\
\hline SAT Index $\left(\mathrm{cm}^{2} / \mathrm{m}^{2}\right)$, median (range) & $84.4(30.5-229.6)$ & $66.2(30.5-137.7)$ & $107.1(44.3 .1-229.6)$ & $<0.0001$ \\
\hline IMAT Index $\left(\mathrm{cm}^{2} / \mathrm{m}^{2}\right)$, median (range) & $0.0(0.0-1.1)$ & $0.0(0.0-1.1)$ & $0.0(0.0-0.7)$ & 0.7 \\
\hline SMD (HU), median (range) & $46.6(13.7-71.2)$ & $45.6(13.7-67.7)$ & $46.6(15.9-71.2)$ & 0.6 \\
\hline Low SMD vs. High SMD & $47(50.5) / 46(49.5)$ & $22(50) / 22(50)$ & $25(51) / 24(49)$ & 0.9 \\
\hline
\end{tabular}

IMAT: Infiltration inter-muscular adipose tissue; SAT: subcutaneous adipose tissue, SMD: skeletal muscle (radio)density; SMI: Skeletal Muscle Index; VAT: visceral adipose tissue. 

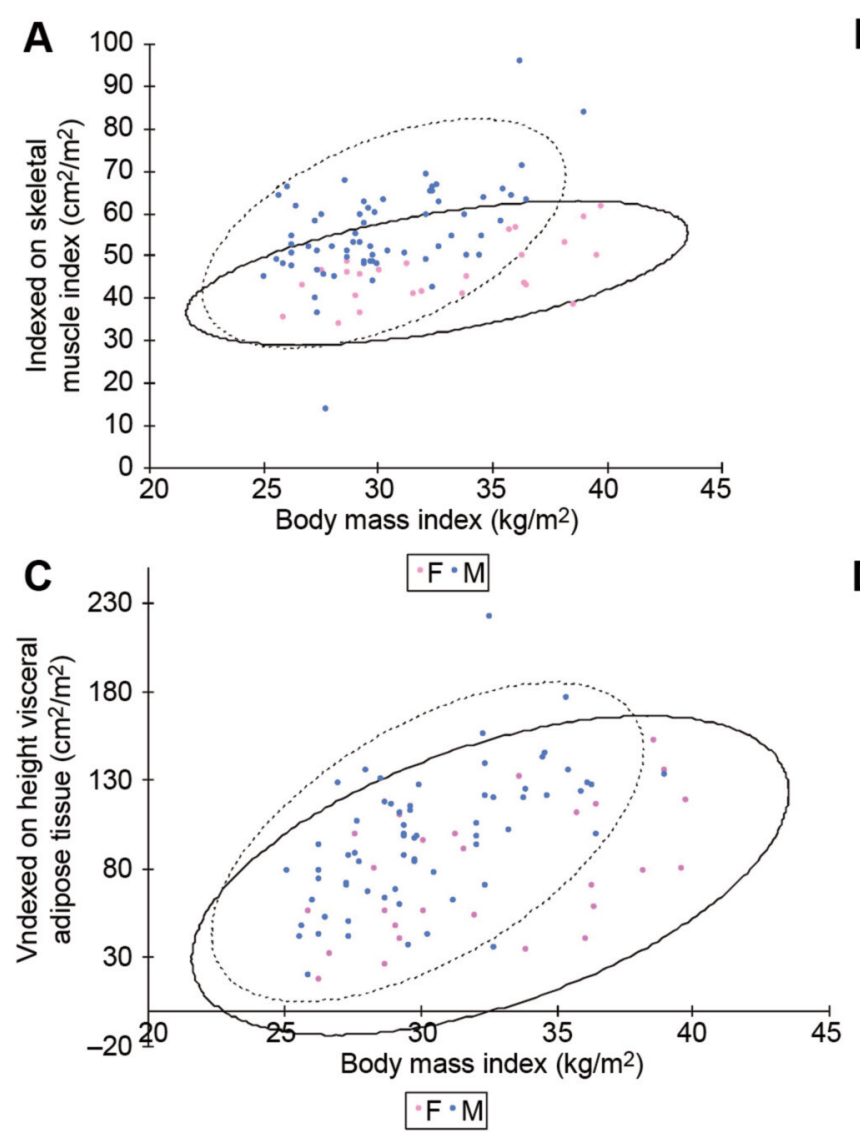

B

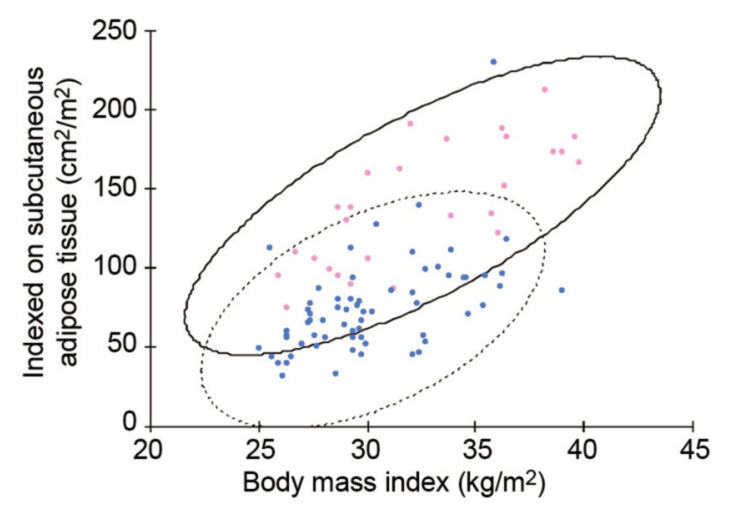

D

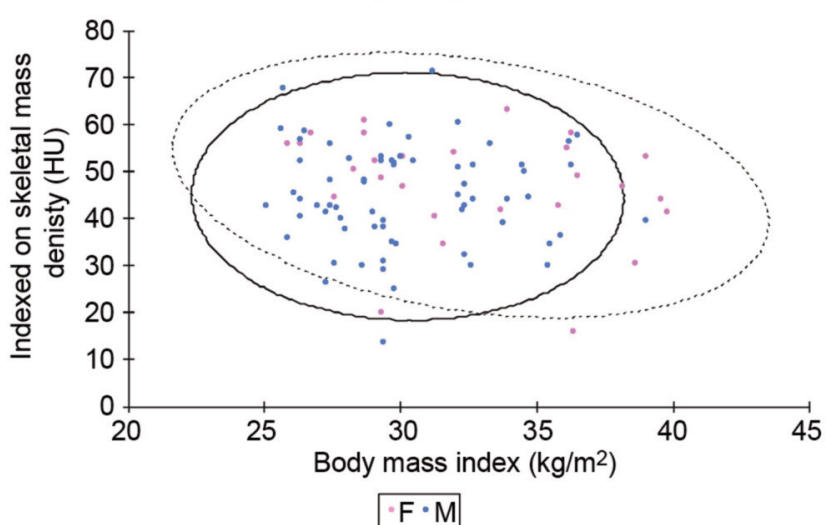

Figure 2. Scatterplot of the relationship between body mass index, body composition and skeletal mass density. Blue dot and dotted line for male patients, pink dot and solid line for female patients, (A) skeletal muscle index; (B) visceral adipose index; (C) subcutaneous adipose index and (D) skeletal mass density.

Table III. Univariate and multivariate analyses of body composition parameters for disease-free survival (DFS) and overall survival (OS).

\begin{tabular}{|c|c|c|c|c|c|c|c|c|}
\hline & \multicolumn{4}{|c|}{ Disease free survival } & \multicolumn{4}{|c|}{ Overall survival } \\
\hline & \multicolumn{2}{|c|}{ Univariate } & \multicolumn{2}{|c|}{ Multivariate } & \multicolumn{2}{|c|}{ Univariate } & \multicolumn{2}{|c|}{ Multivariate } \\
\hline & HR $(95 \% \mathrm{CI})$ & $p$-Value & HR $(95 \% \mathrm{CI})$ & $p$-Value & HR $(95 \% \mathrm{CI})$ & $p$-Value & HR $(95 \% \mathrm{CI})$ & $p$-Value \\
\hline PS: $0-1 v s .2$ & $0.2(0.06-1.1)$ & 0.08 & & & $0.3(0.08-1.5)$ & 0.1 & & \\
\hline Type of surgery: NP vs. NT & $0.3(0.1-1.0)$ & 0.05 & $0.6(0.1-1.8)$ & 0.02 & $0.3(0.1-1.1)$ & 0.09 & & \\
\hline Tumor grade & $2.5(1.4-4.5)$ & 0.001 & $2.3(1.3-4.2)$ & 0.004 & $2.1(1.1-3.9)$ & 0.01 & $1.9(0.9-3.9)$ & 0.05 \\
\hline Stage: pT1-pT2 vs. pT3-pT4 & $0.3(0.12-0.73)$ & 0.004 & $0.4(0.1-0.9)$ & 0.02 & $0.3(0.12-0.73)$ & 0.007 & $0.37(0.1-0.9)$ & 0.04 \\
\hline BMI: obese $v s$. overweight & $1.5(0.7-3.3)$ & 0.2 & & & $0.8(0.3-1.9)$ & 0.7 & & \\
\hline Sarcopenia: yes $v s$. no & $1.0(0.4-2 . »)$ & 0.9 & & & $0.4(0.1-0.9)$ & 0.04 & $0.5(0.2-1.4)$ & 0.1 \\
\hline SMD: low vs. high & $1.7(0.8-3.9)$ & 0.1 & & & $0.8(0.3-2.1)$ & 0.7 & & \\
\hline
\end{tabular}

BMI: Body mass index; NP: partial nephrectomy; NT: total nephrectomy; PS: performance status; SMD: skeletal muscle (radio)density.

occurred significantly more often in obese than overweight patients $(29 \%$ vs. $8 \% ; p=0.007)$. No differences in occurrence of infections were observed according to body composition.
Data on the length of hospital stay after surgery were known for 91 patients. The length of hospital stay was longer in obese than overweight patients ( $22 \%$ vs. $40 \%, p=0.06)$. Body composition did not affect the length of hospital stay. 
A

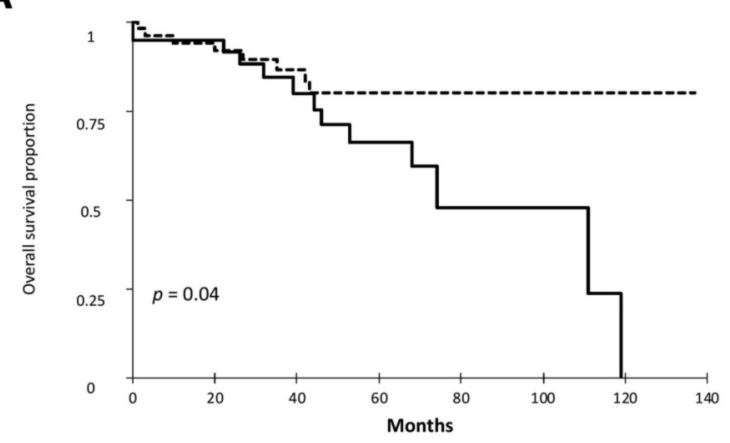

Number at risk $\begin{array}{lllllllll}\text { No sarcopenia } & 53 & 44 & 27 & 18 & 11 & 7 & 3 & 1 \\ \text { Sarcopenia } & 40 & 34 & 19 & 14 & 5 & 2 & 1 & 0\end{array}$

C

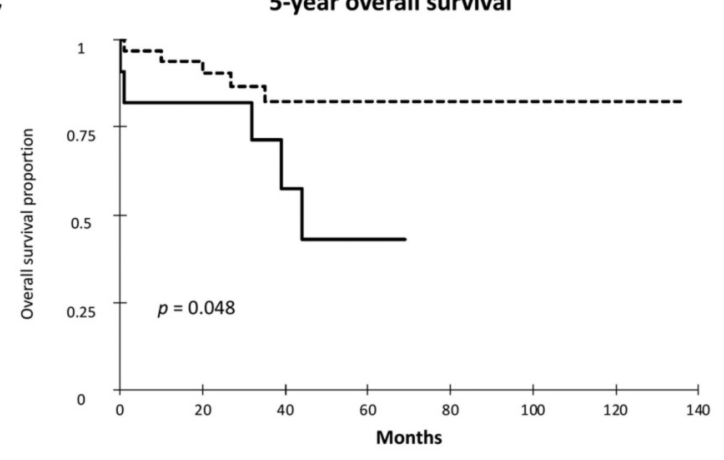

---.-No sarcopenia - Sarcopenia

Number at risk

No sarcopenia Sarcopenia
B
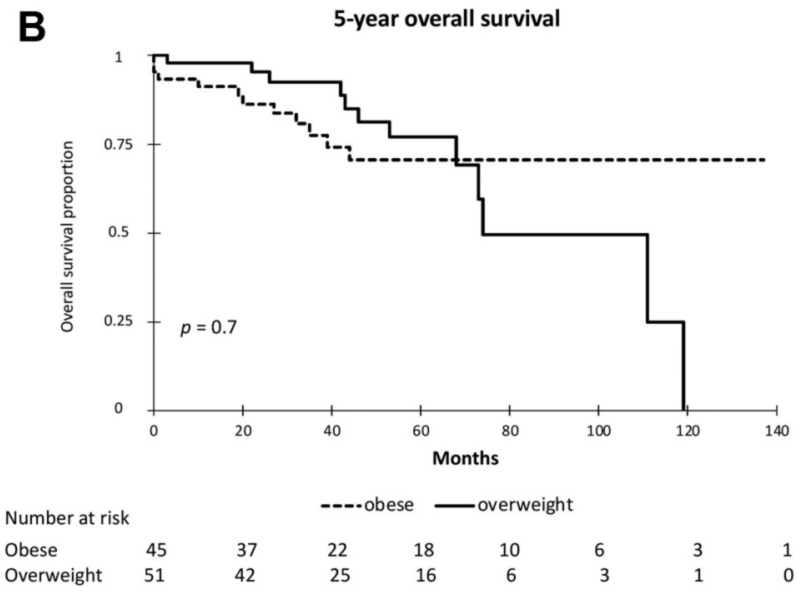

D

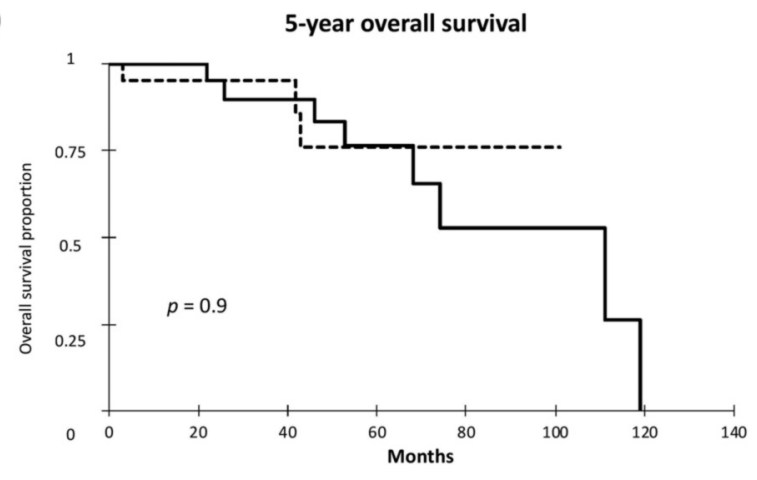

Number at risk

$\begin{array}{lllllllll}\text { No sarcopenia } & 20 & 16 & 10 & 4 & 1 & 1 & 0 & 0\end{array}$

Figure 3. Overall survival curves according to sarcopenia and body mass index. Results were obtained depending on the presence or absence of sarcopenia (A), the body mass index (B), the presence or absence of sarcopenia in obese patients $(C)$, and presence or absence of sarcopenia in overweight patients $(D)$.

Impact of body composition on outcomes. The median follow-up time was 36.5 months (range=0.5-137 months), and 25 patients $(26 \%)$ relapsed. The 5-year DFS rate for the cohort was $61 \%$. Twenty-three patients $(24 \%)$ died. The 5 year OS rates for the cohort was $65 \%$.

In univariate and multivariate analyses, BMI and body composition did not affect 5-year DFS in any of the groups contrary to the classic factors, such as stage, type of surgery, and tumour grade $(p<0.05)$ (Table III).

In univariate analyses, stage, type of surgery, tumour grade and sarcopenia were significantly associated with OS (Figure 3A) but sarcopenia was not an independent prognostic factor in multivariate analyses (Table III). Obese patients tended to have longer survival than overweight patients (Figure 3B).

We further investigated the prognostic value of sarcopenia in the subgroups of BMI. The effect was highlighted in the obese population $(p=0.04)$ but not in the overweight population $(p=0.9)$ (Figure 3C, D).

\section{Discussion}

In our study, we showed that body composition did not affect morbidity or outcomes but BMI was involved in morbidity and there was paradoxically longer survival in the obesity group.

The impact of sarcopenia at diagnosis was assessed in overweight or obese patients for the first time in a localised RCC population, and $40 \%$ patients suffered from sarcopenia.

Martin et al. demonstrated in a large cohort $(n=1,473)$ that the cut-offs should be adapted in patients affected by overweight/obesity compared to other patients (16). We investigated the prevalence of sarcopenia in patients with a BMI $\geq 25 \mathrm{~kg} / \mathrm{m}^{2}$ using cut-offs specific for overweight and 
obese patients with localised RCC. The prevalence of sarcopenia observed in our population was slightly higher in patients with obesity $(25 \%)$ than that reported $(19 \%)$ in subgroups of obese patients with localised RCC (13). However, Psutka et al. used a sarcopenia BMI cut-off $>30$ $\mathrm{kg} / \mathrm{m}^{2}\left(55 \mathrm{~cm}^{2} / \mathrm{m}^{2}\right.$ for men and $39 \mathrm{~cm}^{2} / \mathrm{m}^{2}$ for women) and did not include overweight patients. We also noticed that the incidence of sarcopenia was close to that in patients with urological cancers $(22 \%)(27,28)$.

As we showed that sarcopenia was correlated with BMI, we hypothesize that specific cut-offs should be applied to overweight and obese patients. Similar variability has been observed in patients with metastatic RCC $(11,19)$.

In our study, sarcopenia had no effect on survival in the population. It has been emphasised that the prognostic significance of sarcopenia is evident in patients with locally advanced disease (pT3/4 or $\mathrm{pN}+$ ) but not in those with organ-confined disease (28). Psutka et al. showed that sarcopenia has a negative effect on 5-year OS of patients with localised RCC compared to those without sarcopenia (65\% vs. 74\%, $p=0.005$ ) when they had a worse prognosis (13). In that study, the median disease progression at a median of 0.9 years after surgery contrasts with our study showing a longer DFS. Moreover, sarcopenia is usually a prognostic factor in metastatic RCC (29).

We showed that obese RCC patients had longer survival than non-obese patients. These results support the "obesity paradox" in RCC and the idea that a high BMI is associated with significantly longer cancer-specific survival $(30,31)$. A recent meta-analysis highlighted the opposite association between BMI and mortality in patients with RCC (32). In this subgroup of obese patients, sarcopenia seemed to be a poor prognosis factor, as shown previously (33).

Sarcopenia has been linked with more frequent postoperative complications in patients with other cancers than in those with RCC (10), but it remains unclear in urologic cancer. Unlike Sharma et al. who reported on metastatic RCC (34), we did not observe any effects of sarcopenia on postoperative complications in an adjuvant setting. In others studies, sarcopenia was not associated with postoperative complications in patients with upper-tract urothelial carcinoma and obesity who underwent radical nephroureterectomy (27). We suggest that BMI plays a more important role in postoperative complications than body composition $(35,36)$. In conclusion, weight control might be necessary before surgery for patients with RCC, and more preventive measures for complications should be taken for the obese population compared to overweight patients.

To the best of our knowledge, SMD has only been explored in patients with metastatic $\operatorname{RCC}(9,12,19)$ and only one study has reported that an SMD above the median (38 HU for males and $36 \mathrm{HU}$ for females) is associated with a longer OS (29 vs. 14 months, $p=0.001)$ and longer progression-free survival (8vs. 4 months, $p<0.001$ ) (11). In our study, we did not detect a relation between SMD (median: $46 \mathrm{HU}$ ) and OS.

There are no widely accepted cut-off points to categorise patients as sarcopenic or myosteatosic based on CT measurements. Most studies have used a global cut-off independent of patient characteristics, and skeletal muscle mass and density have differed greatly between studies. One solution could be to develop nomograms based on age, BMI, and/or sex to predict normal skeletal muscle mass and density measures to evaluate the optimal cut-off for skeletal muscle mass and density (37).

In conclusion, body composition did not affect morbidity or progression of localised RCC with a good prognosis. BMI was associated with morbidity and there was paradoxically longer survival in the obese group. A prospective study is needed to confirm the cut-off points and to categorise patients.

\section{Conflicts of Interest}

The Authors declare that they have no competing interests in relation to this study.

\section{Authors' Contributions}

DT, FG, DL participated in the data acquisition. LS did the statistical analysis. DT, DE, and LS analysed the data. DE and TMN supervised the work. DT and DE were the major contributor in writing the manuscript. All Authors contributed to the manuscript, critically revised the manuscript, and approved the final version.

\section{Acknowledgements}

The Authors would like to thank the Gaetan ERRE family for their generous gift for this research. The Authors would also like to thank Textcheck for their assistance with editing the language of this manuscript. The English in this document has been checked by at least two professional editors, both native speakers of English.

For a certificate, please see: http://www.textcheck.com/certificate/ $\mathrm{KuD9gM}$

\section{References}

1 Ries L, Harkins D, Krapcho M, Mariotto A, Miller B, Feuer E, Clegg L, Eisner M, Horner M-J, Howlader N, Hayat M, Hankey B and Edwards B: SEER Cancer Statistics Review, 1975-2003. Public Health Fac Publ, 2006.

2 Morgan TM, Tang D, Stratton KL, Barocas DA, Anderson CB, Gregg JR, Chang SS, Cookson MS, Herrell SD, Smith JA and Clark PE: Preoperative nutritional status is an important predictor of survival in patients undergoing surgery for renal cell carcinoma. Eur Urol 59: 923-928, 2011. PMID: 21295907. DOI: 10.1016/j.eururo.2011.01.034.

3 Andreoli A, Garaci F, Cafarelli FP and Guglielmi G: Body composition in clinical practice. Eur J Radiol 85: 1461-1468, 2016. PMID: 26971404. DOI: 10.1016/j.ejrad.2016.02.005. 
4 Prado CMM, Baracos VE, McCargar LJ, Reiman T, Mourtzakis M, Tonkin K, Mackey JR, Koski S, Pituskin E and Sawyer MB: Sarcopenia as a determinant of chemotherapy toxicity and time to tumor progression in metastatic breast cancer patients receiving capecitabine treatment. Clin Cancer Res 15: 29202926, 2009. PMID: 19351764. DOI: 10.1158/1078-0432.CCR08-2242.

5 Lieffers JR, Bathe OF, Fassbender K, Winget $\mathrm{M}$ and Baracos VE: Sarcopenia is associated with postoperative infection and delayed recovery from colorectal cancer resection surgery. Br J Cancer 107: 931-936, 2012. PMID: 22871883.

6 Deluche E, Leobon S, Desport JC, Venat-Bouvet L, Usseglio J and Tubiana-Mathieu N: Impact of body composition on outcome in patients with early breast cancer. Support Care Cancer 26: 861-868, 2018. PMID: 28948392. DOI: 10.1007/ s00520-017-3902-6.

7 Peyton CC, Heavner MG, Rague JT, Krane LS and Hemal AK: Does sarcopenia impact complications and overall survival in patients undergoing radical nephrectomy for stage III and IV kidney cancer? J Endourol 30: 229-236, 2016. PMID: 26418428. DOI: $10.1089 /$ end .2015 .0492

8 Yip SM, Heng DYC and Tang PA: Review of the interaction between body composition and clinical outcomes in metastatic renal cell cancer treated with targeted therapies. J Kidney Cancer VHL 3: 12-22, 2016. PMID: 28326276. DOI: 10.15586/ jkcvhl.2016.45

9 Fukushima H, Nakanishi Y, Kataoka M, Tobisu K and Koga F: Prognostic significance of sarcopenia in patients with metastatic renal cell carcinoma. J Urol 195: 26-32, 2016. PMID: 26292042. DOI: $10.1016 /$ j.juro.2015.08.071

10 Vrieling A, Kampman E, Knijnenburg NC, Mulders PF, Sedelaar JPM, Baracos VE and Kiemeney LA: Body composition in relation to clinical outcomes in renal cell cancer: a systematic review and meta-analysis. Eur Urol Focus, 2016. PMID: 28753824. DOI: 10.1016/j.euf.2016.11.009

11 Antoun S, Lanoy E, Albiges-Sauvin L and Escudier B: Clinical implications of body composition assessment by computed tomography in metastatic renal cell carcinoma. Expert Rev Anticancer Ther 14: 279-288, 2014. PMID: 24405390. DOI: $10.1586 / 14737140.2013 .866040$

12 Ishihara H, Kondo T, Omae K, Takagi T, Iizuka J, Kobayashi H and Tanabe K: Sarcopenia and the Modified Glasgow Prognostic Score are significant predictors of survival among patients with metastatic renal cell carcinoma who are receiving first-line sunitinib treatment. Target Oncol 11: 605-617, 2016. PMID: 27023922. DOI: $10.1007 / \mathrm{s} 11523-016-0430-0$

13 Psutka SP, Boorjian SA, Moynagh MR, Schmit GD, Costello BA, Thompson RH, Stewart-Merrill SB, Lohse CM, Cheville JC, Leibovich BC and Tollefson MK: Decreased skeletal muscle mass is associated with an increased risk of mortality after radical nephrectomy for localized renal cell cancer. J Urol 195: 270-276, 2016. PMID: 26292038. DOI: 10.1016/j.juro. 2015.08.072

14 Goodpaster BH, Kelley DE, Thaete FL, He J and Ross R: Skeletal muscle attenuation determined by computed tomography is associated with skeletal muscle lipid content. J Appl Physiol 89: 104-110, 2000. PMID: 10904041. DOI: 10.1152/jappl.2000.89.1.104

15 Capitanio U, Bensalah K, Bex A, Boorjian SA, Bray F, Coleman J, Gore JL, Sun M, Wood C and Russo P: Epidemiology of renal cell carcinoma. Eur Urol 75: 74-84, 2019. PMID: 30243799. DOI: $10.1016 /$ j.eururo.2018.08.036

16 Martin L, Birdsell L, Macdonald N, Reiman T, Clandinin MT, McCargar LJ, Murphy R, Ghosh S, Sawyer MB and Baracos VE: Cancer cachexia in the age of obesity: skeletal muscle depletion is a powerful prognostic factor, independent of body mass index. J Clin Oncol 31: 1539-1547, 2013. PMID: 23530101. DOI: $10.1200 / J C O .2012 .45 .2722$

17 Prado CMM, Lieffers JR, McCargar LJ, Reiman T, Sawyer MB, Martin L and Baracos VE: Prevalence and clinical implications of sarcopenic obesity in patients with solid tumours of the respiratory and gastrointestinal tracts: a population-based study. Lancet Oncol 9: 629-635, 2008. PMID: 18539529. DOI: 10.1016/S1470-2045(08)70153-0

18 Carneiro IP, Mazurak VC and Prado CM: Clinical Implications of Sarcopenic Obesity in Cancer. Curr Oncol Rep 18: 62, 2016. PMID: 27541923. DOI: 10.1007/s11912-016-0546-5

19 Antoun S, Lanoy E, Iacovelli R, Albiges-Sauvin L, Loriot Y, Merad-Taoufik M, Fizazi K, di Palma M, Baracos VE and Escudier B: Skeletal muscle density predicts prognosis in patients with metastatic renal cell carcinoma treated with targeted therapies. Cancer 119: 3377-3384, 2013. PMID: 23801109. DOI: $10.1002 / \mathrm{cncr} .28218$

20 Akahori T, Sho M, Kinoshita S, Nagai M, Nishiwada S, Tanaka T, Tamamoto T, Ohbayashi C, Hasegawa M, Kichikawa K and Nakajima Y: Prognostic significance of muscle attenuation in pancreatic cancer patients treated with neoadjuvant chemoradiotherapy. World J Surg 39: 2975-2982, 2015. PMID: 26296840. DOI: $10.1007 / \mathrm{s} 00268-015-3205-3$

21 Hayashi N, Ando Y, Gyawali B, Shimokata T, Maeda O, Fukaya M, Goto H, Nagino M and Kodera Y: Low skeletal muscle density is associated with poor survival in patients who receive chemotherapy for metastatic gastric cancer. Oncol Rep 35: 17271731, 2016. PMID: 26648321. DOI: 10.3892/or.2015.4475

22 Parker WP, Cheville JC, Frank I, Zaid HB, Lohse CM, Boorjian SA, Leibovich BC and Thompson RH: Application of the stage, size, grade, and necrosis (SSIGN) score for clear cell renal cell carcinoma in contemporary patients. Eur Urol 71: 665-673, 2017. PMID: 27287995. DOI: 10.1016/j.eururo.2016.05.034

23 Leibovich BC, Blute ML, Cheville JC, Lohse CM, Frank I, Kwon ED, Weaver AL, Parker AS and Zincke H: Prediction of progression after radical nephrectomy for patients with clear cell renal cell carcinoma: a stratification tool for prospective clinical trials. Cancer 97: 1663-1671, 2003. PMID: 12655523. DOI: 10.1002/cncr.11234

24 Mourtzakis M, Prado CMM, Lieffers JR, Reiman T, McCargar LJ and Baracos VE: A practical and precise approach to quantification of body composition in cancer patients using computed tomography images acquired during routine care. Appl Physiol Nutr Metab 33: 997-1006, 2008. PMID: 18923576. DOI: 10.1139/H08-075

25 Shen W, Punyanitya M, Wang Z, Gallagher D, St-Onge M-P, Albu J, Heymsfield SB and Heshka S: Total body skeletal muscle and adipose tissue volumes: estimation from a single abdominal cross-sectional image. J Appl Physiol 97: 2333-2338, 2004. PMID: 15310748. DOI: 10.1152/japplphysiol.00744.2004

26 Gratzke C, Seitz M, Bayrle F, Schlenker B, Bastian PJ, Haseke N, Bader M, Tilki D, Roosen A, Karl A, Reich O, Khoder WY, Wyler S, Stief CG, Staehler M and Bachmann A: Quality of life and perioperative outcomes after retroperitoneoscopic radical 
nephrectomy (RN), open RN and nephron-sparing surgery in patients with renal cell carcinoma. BJU Int 104: 470-475, 2009. DOI: 10.1111/j.1464-410X.2009.08439

27 Kocher NJ, Jafri S, Balabhadra S, Lehman E, Gardner J, Vijay $\mathrm{K}$, Sarwani N and Raman JD: Is sarcopenia and sarcopenic obesity associated with clinical and pathological outcomes in patients undergoing radical nephroureterectomy? Urol Oncol Semin Orig Investig 36: 156.e17-156.e22, 2018. DOI: 10.1016/ j.urolonc.2017.12.004

28 Fukushima H, Nakanishi Y, Kataoka M, Tobisu K and Koga F: Prognostic significance of sarcopenia in upper tract urothelial carcinoma patients treated with radical nephroureterectomy. Cancer Med 5: 2213-2220, 2016. PMID: 27350148. DOI: $10.1002 / \mathrm{cam} 4.795$

29 Fukushima $\mathrm{H}$ and Koga $\mathrm{F}$ : Impact of sarcopenia in the management of urological cancer patients. Expert Rev Anticancer Ther 17: 455-466, 2017. PMID: 28271727.

30 Choi Y, Park B, Jeong BC, Seo SI, Jeon SS, Choi HY, Adami H$\mathrm{O}$, Lee JE and Lee HM: Body mass index and survival in patients with renal cell carcinoma: a clinical-based cohort and meta-analysis. Int J Cancer 132: 625-634, 2013. PMID: 22610826. DOI: $10.1002 /$ ijc. 27639

31 Donin NM, Pantuck A, Klöpfer P, Bevan P, Fall B, Said J, Belldegrun AS and Chamie K: Body mass index and survival in a prospective randomized trial of localized high-risk renal cell carcinoma. Cancer Epidemiol Prev Biomark 25: 1326-1332, 2016. PMID: 27418270. DOI: 10.1158/1055-9965

32 Zhang J, Chen Q, Li Z-M, Xu X-D, Song A-F and Wang L-S: Association of body mass index with mortality and postoperative survival in renal cell cancer patients, a meta-analysis. Oncotarget 9: 13959-13970, 2018. PMID: 29568408. DOI: 10.18632/ oncotarget. 24210
33 Prado CM, Cushen SJ, Orsso CE and Ryan AM: Sarcopenia and cachexia in the era of obesity: clinical and nutritional impact. Proc Nutr Soc 75: 188-198, 2016. DOI: 10.1017/S00296 65115004279

34 Sharma P, Zargar-Shoshtari K, Caracciolo JT, Fishman M, Poch MA, Pow-Sang J, Sexton WJ and Spiess PE: Sarcopenia as a predictor of overall survival after cytoreductive nephrectomy for metastatic renal cell carcinoma. Urol Oncol 33: 339.e17-23, 2015. PMID: 26094169. DOI: 10.1016/j.urolonc.2015.01.011

35 Anast JW, Stoller ML, Meng MV, Master VA, Mitchell JA, Bassett WW and Kane CJ: Differences in complications and outcomes for obese patients undergoing laparoscopic radical, partial or simple nephrectomy. J Urol 172: 2287-2291, 2004. PMID: 15538250. DOI: 10.1097/01 ju.0000143820.56649.a4

36 Arfi N, Baldini A, Decaussin-Petrucci M, Ecochard R, Ruffion $A$ and Paparel P: Impact of obesity on complications of laparoscopic simple or radical nephrectomy. Curr Urol 8: 149155, 2015. PMID: 26889135. DOI: 10.1159/000365707

37 van Vugt JLA, van Putten Y, van der Kall IM, Buettner S, D'Ancona FCH, Dekker HM, Kimenai HJAN, de Bruin RWF, Warlé MC and IJzermans JNM: Estimated skeletal muscle mass and density values measured on computed tomography examinations in over 1000 living kidney donors. Eur J Clin Nutr, 2018. PMID: 30143785. DOI: 10.1038/s41430-018-0287-7

Received June 2, 2020

Revised June 22, 2020

Accepted June 24, 2020 